\section{Paclobutrazol-induced Leaf, Stem, and Root Anatomical Modifications in Potato}

\author{
Tekalign Tsegaw, S. Hammes, and J. Robbertse \\ University of Pretoria, Plant Production and Soil Science, Lunnon, Duxbury, \\ Pretoria, Guteng 002, South Africa
}

Additional index words. anatomy, starch

\begin{abstract}
Potato (Solanum tuberosum L.) treatment with paclobutrazol resulted in short and compact plants having dark green and thicker leaves, and wider stem and root diameters. Investigating the underlying anatomical modifications in response to the treatment was the objective of the study. Plants of potato cultivar BP 1 were treated with $0,45.0,67.5$, and $90.0 \mathrm{mg}$ paclobutrazol per plant as a foliar spray. A month after treatment leaf, stem and root materials were taken from the control and plants treated with $67.5 \mathrm{mg}$ paclobutrazol, and histological observations were made using light microscope. Leaves of treated plants showed an increased chlorophyll $a$ and $b$ contents, thicker epicuticular wax layer, elongated and thicker epidermal, palisade and spongy mesophyll cells. paclobutrazol increased stem diameter by about $58 \%$ due to induction of thicker cortex, larger vascular bundles, and wider pith diameter associated with larger pith cells. Widening the cortex and the induction of more secondary xylem vessels in response to paclobutrazol treatment increased the root diameter by about $52 \%$. Paclobutrazol treatment remarkably increased the accumulation of starch granules in the stem pith cells and cortical cells of the stem and root. This study is similar to the other relevant studies in reporting an increased leaf thickness, and stem and root diameters; however, most of the underlying anatomical modifications described above have not been reported previously.
\end{abstract}

The regulation of plant growth with synthetic plant growth regulators has become a common agricultural practice. Of the available synthetic plant growth regulators, triazoles are potent at low concentrations to inhibit shoot growth (Davis et al., 1988). Paclobutrazol (PBZ) is a triazole derivative known to interfere with ent-kaurene oxidase activity in the ent-kaurene oxidation pathway leading to a decrease in endogenous GA levels and ABA catabolism (Rademacher, 1997).

PBZ suppressed growth in a wide range of plant species, and treated plants exhibited a dark green colour, and are shorter and more compact in appearance (Terri and Millie, 2000; Sebastian et al., 2002). It induces leaf morphological and anatomical modifications depending on plant species, growth stage, rate and method of application. It reduces leaf area (Sebastian et al., 2002; Yeshitela et al., 2004), increases the thickness of the epicuticular wax layer (Jenks et al., 2001; Sopher et al., 1999), increase size of a vascular bundles, epidermal, mesophyll and bundle sheath cells (Burrows et al., 1992; Sopher et al., 1999). In wheat PBZ increased thickness of the leaves by inducing additional layers of palisade mesophyll cells (Gao et al., 1987).

The reduction of plant height following PBZ treatment is accompanied by various stem

\footnotetext{
Received for publication 11 Dec. 2004. Accepted for publication 23 Jan. 2005. The study was sponsored by the Ethiopian Agricultural Research Training Project (ARTP) of Alemaya University through a fund procured from World Bank. The authors are grateful to J. Coetzee for his permission to work in the Laboratory for Microscopy and Microanalysis. Special thanks goes to N.H. Alan, and R.W. Gilfillan for their unreserved assistance during the laboratory work
}

anatomical alterations depending on species and concentration. Berova and Zlatev (2000) observed increased radial extension in tomato (Lycopersicon esculentum Mill.) stems, but stem diameter was reduced by $12 \%$ to $50 \%$ in citrus root stock seedlings (Yelenosky et al., 1995). McDaniel et al. (1990) reported that PBZ treatment of poinsettia resulted in weaker stems due to the suppression of the thickening of cell wall of phloem fiber caps, decreased width of xylem ring, and restricting the differentiation of interfascicular supporting tissue. In chrysanthemum (Chrysanthemum morifolium), PBZ treatment resulted in thin stems with increased development of secondary xylem and a reduced number of sclerenchyma bundle caps (Burrows etal., 1992). Aguirre and Blanco (1992) observed a decreased proportion of xylem with a corresponding increase in the amount of phloem and cortex in peach shoots (Prunus persica) following PBZ treatment.

Depending on the plant species and the concentration applied, PBZ induces root anatomical and morphological modifications. It increased root diameter in chrysanthemum by increasing the number of rows and diameter of cortical cells (Burrows et al., 1992). PBZ increased root diameter in soybean (Glycine max) by increasing the size of cortical parenchyma cells (Barnes et al., 1989).

Treating potato plants grown under noninductive greenhouse conditions with PBZ resulted in compact plants with thicker, dark green leaves, and wider stem and root diameters (Tekalign and Hammes, 2004). However, information about the underlying anatomical modifications in potato in response to PBZ treatment is scanty. The study was initiated with the major objective of investigating potato leaf, stem and root anatomical modifications following PBZ treatment.
Plant culture. In a greenhouse experiment on the experimental farm of the University of Pretoria, the effect of PBZ on the anatomy of potato leaves, stems and roots was investigated during 2003. Plants of cultivar BP1 were grown in 5-L plastic containers with a mixture of sand and coconut coir (50:50, by volume) as growing medium. During the growing period diurnal temperatures ranged between 17 and $35^{\circ} \mathrm{C}$ and the average relative humidity was $54 \%$. Plants were fertilized with a standard Hoagland solution and watered regularly to avoid water stress.

Treatments. One month afterplanting, during early stolon initiations, the plants were treated with PBZ at rates of $0,45.0,67.5$, and $90.0 \mathrm{mg}$ active ingredient (a.i.) per plant as a foliar spray. (Cultar formulation, $250 \mathrm{~g}$ a.i. PBZ/L, Zeneca Agrochemicals SA (PTY.) Ltd., South Africa). The solution was applied as a fine spray using an atomizer and the control plants were treated with distilled water of equal volume.

Chlorophyll content. Two weeks after treatment, crude leaf chlorophyll extracts were made using $80 \%$ acetone. Spectrophotometer (Pharmacia LKB, Ultrospec III) readings were recorded at 663 and $645 \mathrm{~nm}$, and the concentrations of chlorophyll $a$ and $b$ determined using the specific absorption coefficients recommended by MacKinney (1941).

Morphology and anatomy. Plant height was measured from the base of the stem to the apex. One month after treatment leaf, stem, and root material were collected from the $67.5 \mathrm{mg}$ a.i. PBZ-treated plants and control plants. Leaf material was taken from the mid portion of the third youngest fully expanded leaves. Internode samples were taken from the mid portion of the main stem, and the root samples $1 \mathrm{~cm}$ below the points of attachment to the stem were taken.

Sections of the leaves, stems, and roots were fixed in formalin-acetic acid-alcohol (FAA), dehydrated in increasing ethanol concentrations and embedded in paraffin wax (melting point, $58^{\circ} \mathrm{C}$ ) after substituting the alcohol with xylene (O'Brien and Mc Cully, 1981). Sections of about $8 \mu \mathrm{m}$ were made with a rotary microtome and stained in Safranin 0, counter stained in Fast Green, and mounted in Clear Mount (O'Brien and Mc Cully, 1981). Images were made using a Kodak camera (Nikon DXM 1200; Nikon, Japan) fitted on a light microscope (Nikon Opti. Photo, Nikon, Japan). Measurements of leaf anatomical structures were made using image analyzer (UTHSCSA Image Tool for Window 3.00).

\section{Results}

Leafanatomy. PBZ treated leaves were dark green due to high chlorophyll $a\left(0.82 \mathrm{mg} \cdot \mathrm{g}^{-1}\right.$ fresh weight $)$ and $b\left(0.26 \mathrm{mg} \cdot \mathrm{g}^{-1}\right.$ fresh weight $)$ contents (Table 1). Leaves of the control treatment contained 0.54 and $0.17 \mathrm{mg} \cdot \mathrm{g}^{-1}$ fresh weight chlorophyll $a$ and $b$, respectively. PBZ treated plants exhibited thicker epicuticular wax layers, larger epidermal cells, a single layer of large and elongated palisade mesophyll cells, and a thicker spongy mesophyll tissue (Fig. 1B) compared to the control (Fig. 1A). 
Table 1 Effect of paclobutrazol (PBZ) on leaf, stem, and root characteristics. Mean value of four observations \pm standard deviation.

\begin{tabular}{lccc}
\hline $\begin{array}{l}\text { Plant } \\
\text { part }\end{array}$ & Control & PBZ treated & $\begin{array}{c}\text { Increase over } \\
\text { the control }(\%)\end{array}$ \\
\hline Leaf & & & \\
Chlorophyll a $\left(\mathrm{mg} \cdot \mathrm{g}^{-1}\right.$ fresh weight) & $0.54 \pm 0.05$ & $0.82 \pm 0.09$ & 51.8 \\
Chlorophyll $\mathrm{b}\left(\mathrm{mg} \cdot \mathrm{g}^{-1}\right.$ fresh weight) & $0.17 \pm 0.03$ & $0.26 \pm 0.08$ & 52.9 \\
Total thickness $(\mu \mathrm{m})$ & $215.4 \pm 5.1$ & $267.8 \pm 6.7$ & 24.3 \\
Epidermal cell length $(\mu \mathrm{m})$ & $34.2 \pm 13.9$ & $42.3 \pm 12.5$ & 23.7 \\
Epidermal cell width $(\mu \mathrm{m})$ & $12.3 \pm 3.4$ & $14.0 \pm 3.0$ & 13.8 \\
$\quad$ Palisade cell length $(\mu \mathrm{m})$ & $87.6 \pm 5.8$ & $116.3 \pm 6.4$ & 32.7 \\
Palisade cell width $(\mu \mathrm{m})$ & $14.9 \pm 2.6$ & $21.1 \pm 3.1$ & 41.6 \\
$\quad$ Spongy mesophyll thickness $(\mu \mathrm{m})$ & $95.6 \pm 7.9$ & $110.3 \pm 8.0$ & 15.4 \\
Stem & & & \\
$\quad$ Stem length $(\mathrm{cm})$ & $76.4 \pm 1.7$ & $43.5 \pm 2.3$ & -43.1 \\
Stem diameter $(\mathrm{mm})$ & $6.6 \pm 0.5$ & $10.4 \pm 1.2$ & 57.6 \\
Root & & & \\
Root diameter $(\mathrm{mm})$ & $2.9 \pm 0.2$ & $4.4 \pm 2.1$ & 51.7 \\
\hline
\end{tabular}

Leaf thickness increased from $215 \mu \mathrm{m}$ to $268 \mu \mathrm{m}$ in response to PBZ treatment (Table 1). PBZ increased the length and diameter of epidermal cells by about 24 and $14 \%$, respectively over the control. PBZ treatment increased leaf palisade mesophyll cell length and width. The mean palisade mesophyll cell length and diameter of the treated leaves were about 116 and $21 \mu \mathrm{m}$, while 87 and $15 \mu \mathrm{m}$ for the untreated leaves, respectively. PBZ treatment increased the thickness of spongy mesophyll by about $15 \%$ over the control, $96 \mu \mathrm{m}$ thick.

Stem morphology and anatomy. PBZ treatment resulted in shorter and thicker stems compared to the control plants (Table 1 and Fig. 2). The mean plant height was reduced from 76.4 to $43.5 \mathrm{~cm}$ in response to PBZ treatment while stem diameter was increased by $58 \%$ over the control. This is attributed to the induction of a thicker cortex, well-developed vascular bundles, and a larger pith diameter in response to the treatment (Fig. 3B). The stem of PBZ treated plants had larger symmetrical pith cells containing numerous starch granules (Fig. 3D) while the control plants exhibited smaller irregularly shaped pith cells almost devoid of starch granules (Fig. 3C).

Root anatomy. The average root diameter of PBZ treated plants was $4.4 \mathrm{~mm}, 52 \%$ thicker than the $2.9 \mathrm{~mm}$ of the control (Table 1). PBZ increased the width of cortex and favoured the induction of more secondary xylem vessels compared to the control (Fig. 4A and B). Roots of treated plants developed larger cortical cells containing numerous starch granules (Fig. 4D) while the untreated plants possessed thin and elongated cortical cells with few starch granules (Fig. 4C).

\section{Discussion}

PBZ-treated potato plants exhibited a dark green colour due to high chlorophyll $a$ and $b$ contents. The increase in chlorophyll content may be attributed to an enhanced chlorophyll synthesis and/or more densely packed chloroplasts per unit leaf area. Sebastian et al. (2002) reported enhanced chlorophyll synthesis in Dianthus caryophyllus and Khalil (1995) observed more densely packed chloroplasts per unit leaf area in response to PBZ treatment. Increased chlorophyll content in potato due to PBZ treatment was observed by Balamani and Poovaiah (1985) and Bandara and Tanino (1995). The higher chlorophyll content of treated potato leaves may be related to the influence of PBZ on endogenous cytokinin levels. It has been proposed that PBZ stimulates cytokinin synthesis that enhances chloroplast differentiation, chlorophyll biosynthesis, and prevents chlorophyll degradation (Fletcher et al., 1982). GA biosynthesis inhibitors increased cytokinin content in soybean (Glycine max) (Grossman, 1992) and Dianthus caryophyllus (Sebastian et al., 2002). PBZ considerably delayed the onset of senescence in grapevines and treated plants retained photosynthetically active leaves the control (A). Scale bar $=100 \mu \mathrm{m}$. longer than the untreated plants (Hunter and Proctor, 1992).

The observed higher epicuticular wax deposition in treated leaves may be related to the increase in endogenous ABA levels in response to PBZ treatment (Rademacher, 1997). An increase in ABA stimulates the synthesis of lipid transfer proteins in barley (Hordeum vulgare) that play an important role in the formation of epicuticular waxes, a process that affects the water relation of the leaves (Hollenbach et al., 1997). PBZ treatments caused a $10 \%$ increase in total wax load and changes in the proportion of certain wax constituents in potted rose cultivars within $11 \mathrm{~d}$ of application (Jenks et al., 2001). The development of a thicker epicuticular wax layer provides better protection against some plant pathogens and minor mechanical damage (Kolattukudy, 1987).

The observed increased in leaf thickness

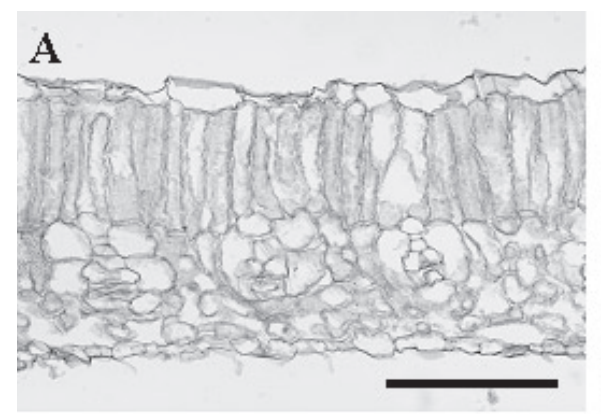
was attributed to an increase in epidermal cell diameter, palisade cell length and spongy mesophyll depth. Burrows et al. (1992) reported that increased chrysanthemum (Chrysanthemum morifolium) leaf thickness in response to PBZ treatment was due to thicker spongy mesophyll, and the induction of additional layers of palisade parenchyma, although individual cells were shorter, of small diameter and more tightly packed. In maize (Zea mays L.) PBZ treated leaves showed more epicuticular wax deposition and were thicker and broader ow-

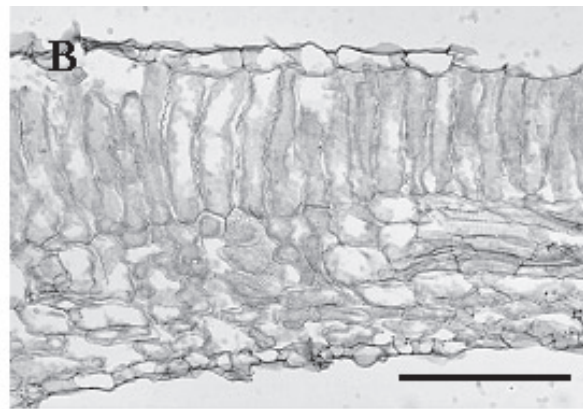

Fig. 1. Light micrographs of transverse sections of leaves showing thicker epicuticular wax and enlarged epidermal, palisade mesophyll, and spongy mesophyll cells of paclobutrazol-treated (B) compared to

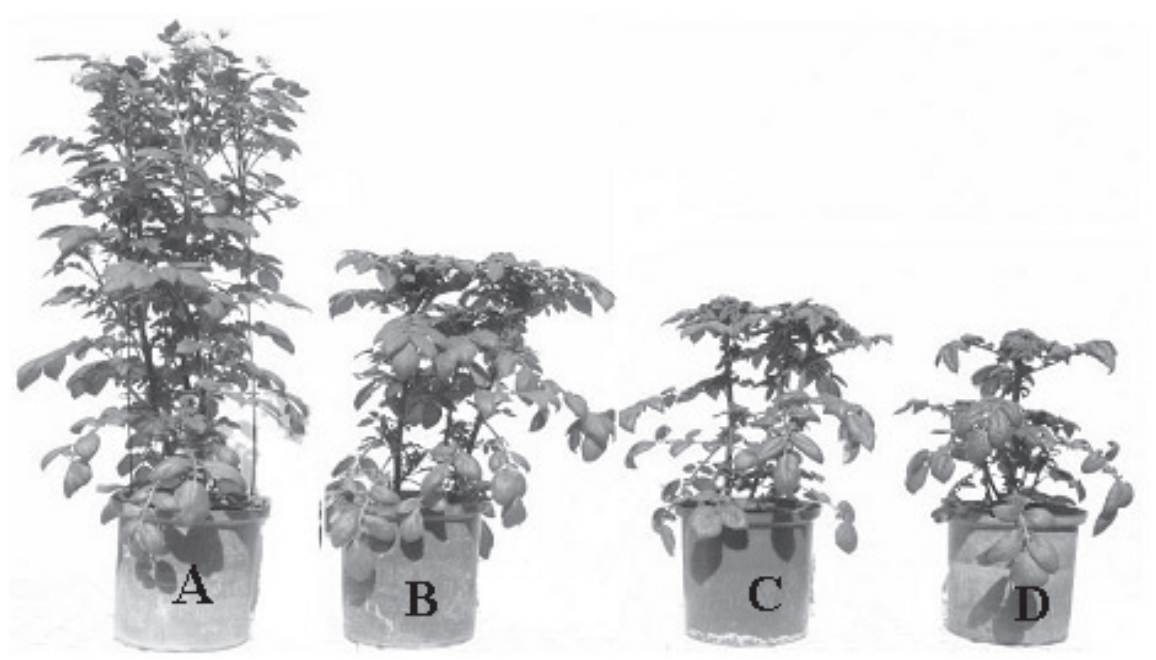

Fig. 2. Potato plant height reductions in response to paclobutrazol (PBZ) treatment. (A) Untreated, (B) 45 $\mathrm{mg}$ a.i. PBZ, (C) $67.5 \mathrm{mg}$ a.i. PBZ, and (D) $90 \mathrm{mg}$ a.i. PBZ. 
ing to enlarged vascular elements, epidermal, mesophyll, and bundle sheath cells (Sopher et al., 1999). Hawkins et al. (1985) reported a $15 \%$ to $24 \%$ increase in soybean leaf thickness due to the elongation of the palisade cells without affecting the number of palisade rows and spongy parenchyma thickness. Dalziel and Lawrence (1984) reported that PBZ induced a $100 \%$ increase in sugar beet leaf thickness due to a three to four fold increase in palisade cell length, without affecting the number of rows.
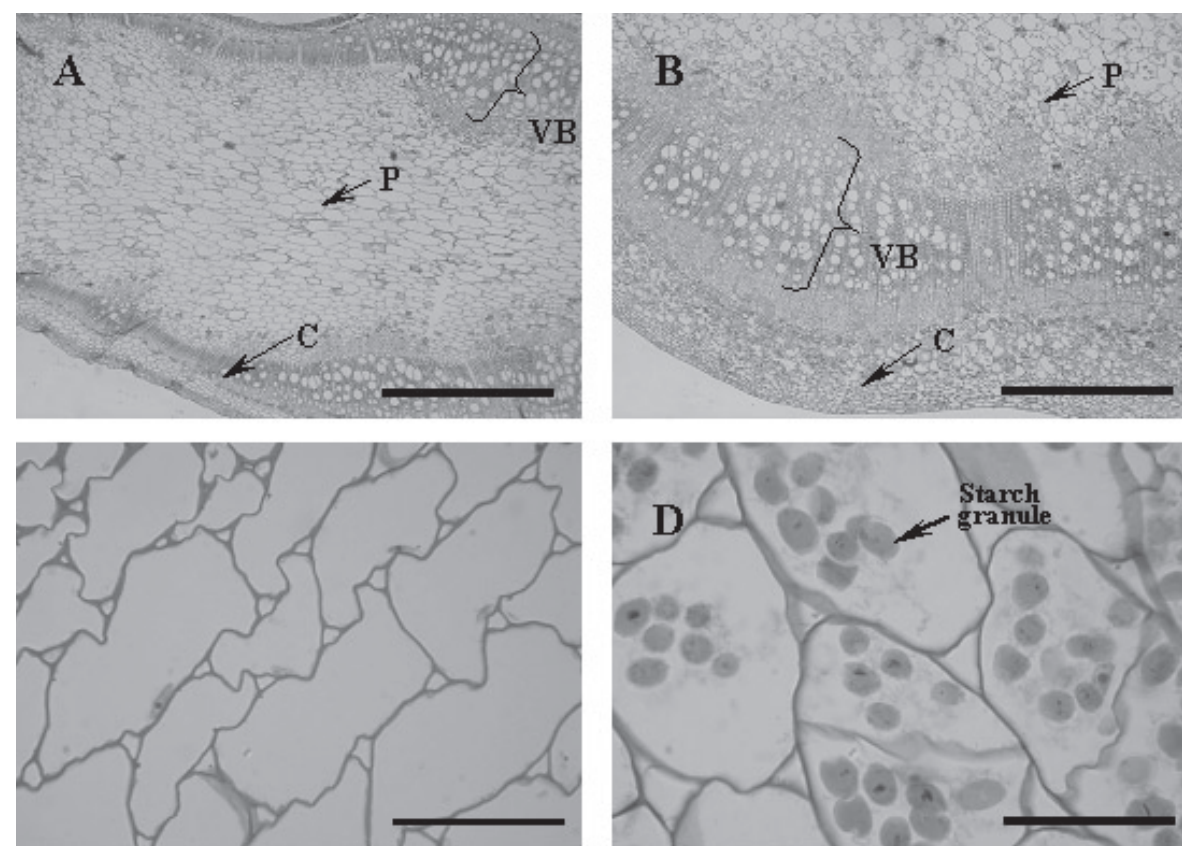

Fig. 3. Transverse micrographs of sections from the stems of the control and paclobutrazol-treated potato plants. The treated stem $(\mathbf{B})$ is characterized by increased cortex thickness $(\mathbf{C})$, well-developed vascular bundles (VB), and wider pith diameter (P) compared to the control (A). Treated plants developed larger, oval-shaped pith cells cotaining starch granuals (D) compared to the smaller and irregularly shaped pith cells without starch granuals $(\mathbf{C})$. Scale bar $=100 \mu \mathrm{m}$.
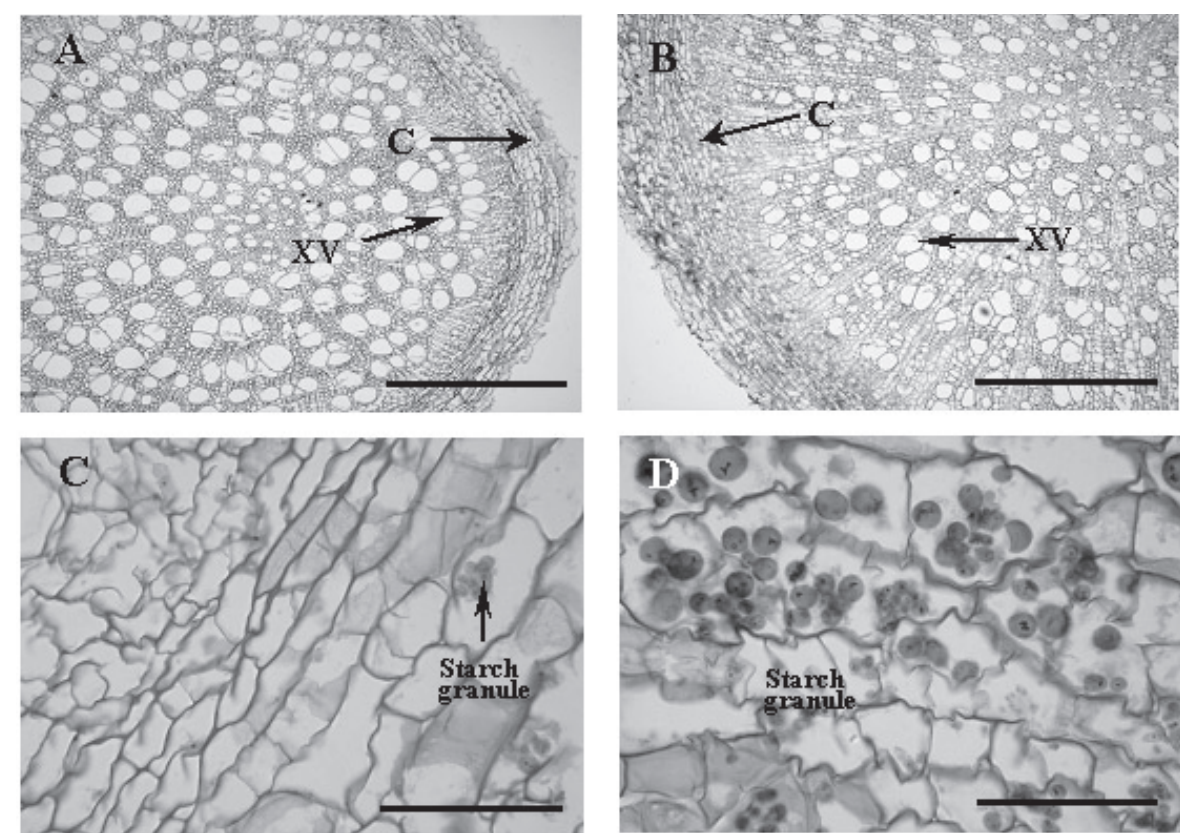

Fig. 4. Transverse sections of roots of the control and paclobutrazol-treated potato plants. Treated plants (B) had larger root diameters due to widening of cortex (C) and the induction of more secondary xylem vessels (XV) compared to the control (A). larger root cortical cells of treated plants contained more starch granuals (D) than to the smaller cortical cells of the control plants (C). Scale bar $=100 \mu \mathrm{m}$. and Loy (1976) showed that GA promote cell division by stimulating cells in the $\mathrm{G}_{1}$ phase to enter the $\mathrm{S}$ phase and by shortening the duration of S phase. They concluded that increased cell numbers lead to more rapid stem growth. Similar reductions in shoot growth were reported in scaevola (Terri and Millie, 2000) and $D i$ anthus caryophyllus (Sebastian et al., 2002) in response to PBZ treatment. More recently, Suzuki etal. (2004) reported that the presence of PBZ in the medium strongly inhibited etiolated and nonetiolated longitudinal shoot growth of Catasetum fimbriatum.

PBZ treatment increased cortex thickness, size of the vascular bundles, and pith diameter and resulted thicker stems. This modification may be attributed to radial expansion of cells due to reduced endogenous GA activities in response to the treatment. Wenzel et al. (2000) reported that GA limits the extent of radial expansion of plant organs. In dicot stems, cell shape alterations are apparently caused by a more longitudinal orientation of cellulose microfibrils being deposited in the cell walls, preventing expansion parallel to the these microfibrils but allowing expansion perpendicular to them (Eisinger, 1983). PBZ promoted radial expansion of the pea (Pisum sativum L.) cells (Wang and Lin, 1992). The nonuniform distribution and arrangement of the vascular elements in the potato stems resulted in irregularity in the shape of the stems. Various authors reported different results in various plant species with respect to PBZ induced stem anatomical modifications. PBZ reduced both cell number and length in safflower (Carthamus tinctorius L.) stem (Potter et al., 1993). Burrows et al. (1992) reported that PBZ treatment brought about a $50 \%$ reduction in chrysanthemum stem diameter because of an enhanced development of secondary xylem and a marked reduction in the number of sclerenchyma bundle caps. In peach (Prunus persica) shoots, PBZ reduced the proportion of xylem and increased that of phloem and cortex, and increased xylem density (Aguirre and Blanco, 1992). In an investigation on poinsettia, McDaniel et al. (1990) found that PBZ suppressed cell wall thickening in the phloem fiber caps, decreased the width of xylem ring, and restricted the differentiation of interfasicular supporting tissues.

It was observed that untreated plants had more thinner and longer roots compared to the treated plants. PBZ increased root diameter by increasing the width of cortex and by enhancing the formation of more secondary xylem vessels. Depending on the plant species and the concentration, PBZ either stimulated or inhibited root growth. PBZ caused thickening of maize roots and increased their starch content (Baluska et al., 1993). Treating primary roots of pea with PBZ inhibited root extension (Wang and Lin, 1992). Increased root diameter has been correlated with larger cortical parenchyma cells in soybean and maize (Barnes et al., 1989). Increasing root diameter in chrysanthemum may be due to an increase the number of rows and diameter of cortical cells (Burrows et al., 1992). A stimulatory effect of PBZ on root growth has also reported in English ivy 
(Geneve, 1990) and mung bean (Porlingis and Koukourikou-Petridou, 1996).

PBZ increased the accumulation of starch granules in the pith cells of the stem, and in the cortical cells of roots. It is postulated that the increase in the number of starch granules may be attributed to PBZ stimulated reduction in GA activity. Under favorable conditions for tuberization (GA content below threshold level), the activities of enzymes involved in potato tuber starch biosynthesis such as ADPGpyrophosphorylase, starch phosphorylase and starch synthase increase (Visser et al., 1994; Appeldoorn et al., 1997). Mares et al. (1981) observed that exogenous application of $\mathrm{GA}_{3}$ on growing tubers substantially reduced the activity of ADPG-pyrophosphorylase, while the activity of starch phosphorylase remained more or less constant. Booth and Lovell (1972) reported that application of $\mathrm{GA}_{3}$ to potato shoots reduced starch accumulation in the tubers. PBZ treatment increased root starch content in maize plants (Baluska et al., 1993). PBZ treatment increased starch accumulation in the leaves, stems, crowns and roots of rice seedling while $\mathrm{GA}_{3}$ treatment decreased starch accumulation in the leaves and crowns of the seedlings (Yim et al., 1997).

PBZ modified the morphology of the potato plant in such a way that treated plants appeared to be dark green, and short and compact. It induced anatomical alterations such as increasing leaf thickness as well as the diameter of the stems and roots. It enhanced starch synthesis in the pith cells of the stem and cortical cells of the stems and roots. This study confirms that PBZ treatment can induce similar morphological and anatomical modifications in a wide range of plant species. The effect of PBZ on the induction of morphological and anatomical modifications may be mediated by changing the hormonal balance of the plant.

\section{Literature Cited}

Aguirre, R. and A. Blanco. 1992. Pattern of histological differentiation induced by paclobutrazol and $\mathrm{GA}_{3}$ in peach shoots. Acta Hort. 315:7-12.

Appeldoorn, N.J.G., S.M. de Bruijn, E.A.M. KootGronsveld, R.G.F. Visser, D. Vreugdenhil, and L.H.W. Van der Plas. 1997. Developmental changes of enzymes involved in sucrose to hexose-phosphate conversion during early tuberization of potato. Planta 202:220-226.

Balamani, V. and B.W. Poovaiah. 1985. Retardation of shoot growth and promotion of tuber growth of potato plants by paclobutrazol. Amer. Potato J. 62:363-369.

Baluska, F., J.S. Parker, and P.W. Barlow. 1993. A role of gibberellic acid in orienting microtubules and regulating cell polarity in the maize cortex. Planta 191:149-157.

Bandara, P.M.S. and K.K. Tanino. 1995. Paclobutrazol enhances mini tuber production in Norland potatoes. J. Plant Growth Regulat. 14:151-155

Barnes, A.M., R.H. Walser and T.D. Davis. 1989. Anatomy of Zea mays and Glycine max seedling treated with triazole plant growth regulators. Biol. Plant. 31:370-375.

Berova, M. and Z. Zlatev. 2000. Physiological response and yield of paclobutrazol treated tomato plants (Lycopersicon esculentum Mill). Plant Growth Regulat. 30(2):117-123.
Booth, A. and P.H. Lovell. 1972. The effect of pretreatment with gibberellic acid on the distribution of photosynthate in intact and disbudded plants of Solanum tuberosum L. New Phytol. 71:795-804.

Burrows, G.E., T.S. Boag, and W.P. Stewart. 1992. Changes in leaf, stem, and root anatomy of chrysanthemum cv. Lillian Hoek following paclobutrazol application. J. Plant Growth Regulat. 11:189-194.

Dalziel, J. and D.K. Lawrence. 1984. Biochemical and biological effects of kaurene oxidase inhibitors, such as paclobutrazol. Britain Plant Growth Regulat. Group, Monograph 11:43-57.

Davis, T.D. and E.A. Curry. 1991. Chemical regulation of vegetative growth. Crit. Rev. Plant Sciences 10:151-188.

Davis, T.D., G.L. Steffens, and N. Sankhla. 1988. Triazole plant growth regulators. Hort. Rev. 10:63-105.

Eisinger, W. 1983. Regulation of pea internode expansion by ethylene. Annu. Rev. Plant Physiol. 34:225-240.

Fletcher, R.A., V. Kallidumbil, and P. Steele. 1982.An improved bioassay for cytokinin using cucumber cotyledons. Plant Physiol. 69:675-677.

Gao, J., G. Hofstra, and R.A. Fletcher. 1987. Anatomical changes induced by triazoles in wheat seedlings. Can. J. Bot. 66:1178-1185.

Geneve, R.L. 1990. Root formation in cuttings of English ivy treated with paclobutrazol or uniconazole. HortScience 25:709.

Grossman, K. 1992. Plant growth retardants: Their mode of action and benefit for physiological research, p. 788-797. In: C.M. Karssen, L.C. Van Loon, and D. Vreugdenhil (eds.). Progress in plant growth regulations. Kluwer Academic Publ., The Netherlands.

Hawkins, A.F., H.K. Hughes, and C.A. Hart. 1985. Effects of the growth regulator, paclobutrazol, on structure and photosynthesis of soybean leaves. Britain Plant Growth Regulat. Group Monogr. 12:127-142.

Hollenbach, B., L. Schreiber, W. Hartung, and K.J. Dietz. 1997. Cadmium leads to stimulated expression of lipid transfer protein (ltp) in barley: Implications for the involvement of LTP in wax assembly. Planta 203:9-19.

Hunter, D.M. and J.K.A. Proctor. 1992. Paclobutrazol affects growth and fruit composition of potted grapevines. HortScience 27:319-321.

Jenks, M.A., L. Andersen, R.S. Teusink, and M.H. Williams. 2001. Leaf cuticular waxes of potted rose cultivars as affected by plant development, drought and paclobutrazol treatments. Physiol. Plant. 112:62-70.

Khalil, I.A. 1995. Chlorophyll and carotenoid contents in cereals as affected by growth retardants of triazole series. Cereal Res. Comm. 23:183-189.

Kolattukudy, P.E. 1987. Lipid-derived defensive polymers and waxes and their role in plant microbe interaction, p. 291-314. In: P.K. Stumpf (ed.). The metabolism, structure and function of plant lipids. Plenum Press, New York.

Liu, P.B.W. and J.B. Loy. 1976. Action of gibberellic acid on cell proliferation in the sub apical shoot meristem of watermelon seedlings. Amer. J. Bot. 63:700-704

MacKinney, G. 1941. Absorption of light by chlorophyll solutions. J. Biol. Chem. 140:315-322.

Mares, D.J., H. Marschner, and A. Krauss. 1981. Effect of gibberellic acid on the growth and carbohydrate metabolism of developing tubers of potato (Solanum tuberosum L.). Physiol. Plant. 52:267-274.

McDaniel, G.L., E.T. Graham, and K.R. Maleug.
1990. Alteration of poinsettia stem anatomy by growth-retarding chemicals. HortScience 25:433-435.

O'Brien, T.P. and M.E. Mc Cully. 1981. The study of plant structure principles and selected methods. Prentice-Hall of Australia Pty. Ltd., Sydney, Australia.

Porlingis, I.C. and M. Koukourikou-Petridou. 1996. Promotion of adventitious root formation in mung bean cutting by four triazole growth retardants. HortScience 71:573-579.

Potter, T.I., K.P. Zanewich, and S.B. Rood. 1993. Gibberellinbiosynthesis of safflower:Endogenous gibberellins and response to gibberellic acid. Plant Growth Regulat. 12:133-140.

Rademacher, W. 1997. Bioregulation of crop plants with inhibitors of gibberellin biosynthesis. Proc. Plant Growth Regulat. Soc. Amer. 24:27-31.

Salisbury, F.B. and C.W. Ross 1992. Hormones and growth regulators: Auxins and gibberellins, $\mathrm{p}$. 357-372. In: Plant physiology. 4th ed. Wadsworth Publ. Co., Calif.

Sebastian, B., G. Alberto, A.C. Emilio, A.F. Jose, and A.F. Juan. 2002. Growth, development and color response of potted Dianthus caryophyllus cv. Mondriaan to paclobutrazol treatment. Sci. Hort. 1767:1-7.

Sopher, C.R., M. Kròl, N.P.A. Huner, A.E. Moore, and R.S. Fletcher. 1999. Chloroplastic changes associated with paclobutrazol-induced stress protection in maize seedling. Can. J. Bot. 77(2):279-290.

Suzuki, R.M., G.B. Kerbauy, and G.R. Zaffari. 2004. Endogenous hormonal levels and growth of dark-incubated shoots of Catasetum fimbriatum. J. Plant Physiol. 161:929-935.

Tekalign, T. and P.S. Hammes. 2004. Response of potato grown under non-inductive condition to paclobutrazol: shoot growth, chlorophyll content, net photosynthesis, assimilate partitioning, tuber yield, quality, and dormancy. Plant Growth Regulat. 43:227-236.

Terri, W.S. and S.W. Millie. 2000. Growth retardants affect growth and flowering of Scaevola. HortScience 35(1):36-38.

Visser, R.G.F., D. Vreugdenhil, T. Hendrix, and E. Jacobsen. 1994. Gene expression and carbohydrate content during stolon to tuber transition in potatoes (Solanum tuberosum L.). Physiol. Plant. 90:285-292.

Wang, L.H. and C.H. Lin. 1992. The effect of paclobutrazol on physiology and biochemical changes in primary roots of pea. J. Expt. Bot. 43:1367-1372.

Wenzel, C., R.E Williamson, and G.O Wasteneys. 2000. Gibberellin induced changes in growth anisotropy precede gibberellin dependent changes in cortical microtubule orientation in developing epidermal cells of barley leaves. Kinematics and cytological studies on gibberellin-responsive dwarf mutant, M489. Plant Physiol. 124:813-822.

Yelenosky, G., J.C.V. Vu, and H.K. Wutscher. 1995. Influence of paclobutrazol in the soil on growth, nutrient elements in the leaves, and flood/freeze tolerance of citrus rootstock seedlings. J. Plant Growth Regulat. 14:129-134.

Yeshitela, T., P.J Robbertse, and P.J.C. Stassen. 2004. Paclobutrazol suppressed vegetative growth and improved yield as well as fruit quality of 'Tommy Atkins' mango (Mangifera indica) in Ethiopia. N.Z. J. Crop Hort. Sci. 32:281-293.

Yim, K.O., Y.W. Kwon, and D.E. Bayer. 1997. Growth responses and allocation of assimilates of rice seedlings by paclobutrazol and gibberellin treatment. J. Plant Growth Regulat. 16:35-41. 